\title{
Safe Transplantation of Pluripotent Stem Cell by Preventing Teratoma Formation
}

\author{
Rashin Mohseni ${ }^{1}$, Amir Ali Hamidieh ${ }^{1,2}$, Javad Verdi ${ }^{1}$ and Alireza Shoae-Hassani ${ }^{\text {** }}$
}

${ }^{1}$ Applied Cell Sciences department, School of Advanced Technologies in Medicine, Tehran University of Medical Sciences, Tehran, Iran ${ }^{2}$ Hematology, Oncology and Stem cell Transplantation Research Center, Tehran University of Medical Sciences, Tehran, Iran

\begin{abstract}
As the renewable source of all cell types in the human body, embryonic stem cells (ESCs) and induced pluripotent stem cells (iPSCs) hold great promise for regenerative medicine and cell therapy. However, one major obstacle to the clinical application of these pluripotent stem cells (PSCs) is that these kinds of stem cells remaining with their differentiated derivatives pose cancer risk by forming teratomas after transplantation. The microenvironment niches of PSCs are crucial for teratoma formation and its progression. The high expression of some oncogenes like $c M y c$ and Klf4 are involved in the teratoma formation process. The kinetics of the teratoma and tumor formation after transplantation is depends on the number of remaining PSCs and it could take a long time for a small number of PSCs to form teratomas. Therefore, the batch-to-batch deviation in the lineage specific differentiation will make it a tediously long and not decisive attempt to evaluate the teratoma risk of the PSC-derived cells prepared for therapeutic approaches. The removal of undifferentiated PSCs could be achieved by some ways such as destroying the remained undifferentiated PSCs from tissue and the differentiated cell population, removing PSCs during the differentiation procedure, inducing complete differentiation of leftover undifferentiated PSCs and inhibition from the dedifferentiating process for committed cells. Therefore for this purpose we could use many techniques including monoclonal antibodies, small molecules, anti-angiogenic agents, suicide genes and pharmacological agents to eliminate undifferentiated PSCs and inhibit teratomas. Overalls, an efficient approach beyond the mentioned points in this article to eliminate the teratoma risk associated with PSCs would greatly facilitate the development of the ESC/ iPSC-based cell therapy.
\end{abstract}

Keywords: Cell therapy; iPS; Regenerative medicine; Pluripotent; Stem cell; Teratoma; Transplantation

\section{Pluripotent Stem Cells and Teratoma Formation}

Stem cells continuously turn toward the choices of self-renewing, differentiation, migration, quiescence and finally death [1-3]. The embryonic stem cells (ESCs) and their counterparts induced pluripotent stem cells (iPSCs) go through unlimited self-renewal and pluripotency to differentiate into all cell types from all lineages in the body. Therefore, as a renewable source of cells, ESCs and iPSCs possess great promise for the regenerative medicine and cell therapy of human diseases that have no cure in the current state. Human iPSCs are the potential source of patient-specific pluripotent stem cells (PSCs) and have tremendous value for therapeutic purposes $[4,5]$. However, some serious obstacles must be overcome before the PSC therapies could enter the clinics. These main obstacles include immunogenicity and the teratoma risk that even a few contaminating undifferentiated PSCs within their differentiated derivatives may form teratomas (A non-cancerous tumor) after transplantation [6,7]. As PSCs can form teratomas in vivo, this may cause cancer when differentiated cells contaminated with ESCs are transplanted into human organs (Figure 1). Teratoma formation and spreading requires some molecular processes such as self-renewal, lack of contact inhibition and telomerase activity [6]. Also the degree of difference in histocompatibility between donor cells and recipients, the immunosuppressive regiments of the recipients, differentiation protocols and selection strategies has significant importances. The site of transplantation (immune-privilege organs) is a main factor in the teratoma formation. In 2006, Cooke et al., described that the injection under the kidney capsule having the highest success rate and producing the largest teratoma sizes due to its rich vascular bed [8]. Teratoma formation in the lung and thymus had the highest while the pancreas was partially site privileged [9]. Based on some researches the rate of teratoma formation is as follows: subcutaneous $25-100 \%$; intratesticular
60\%; intramuscular $12.5 \%$ and under the kidney capsule $100 \%$ [10]. Also the high expression of some oncogenes like $c M y c$ and Klf4 are involved in the teratoma formation process [11]. In fact formation of three somatic germ layers within the teratoma is taken as the best indicator of the pluripotency of cell lines [12]. But a case report on the teratoma development in a child receiving fetal neural stem cell for treatment of ataxia telangiectasia emphasizes this risk [13], although it has been reported previously that sorting of cells expressing the neural precursor marker Sox1 before transplantation has been reduced the risk of teratoma formation [14,15]. In 2009, Geron Company received a temporary FDA hold on the first ever FDA-approved clinical trial using ESC for spinal cord injury after observing a few incidents of animals developing microscopic, nonproliferative cysts at the lesion sites [16]. The situation for iPSCs is more complex as they integrated by viruses carrying Oct4, Sox2, Myc and krupple-like factor 4 (Klf4) transcription factors [4]. Although the viral integration has no direct effect to the reprogramming process, the genomic alterations and the risk of reactivation of the transgenes during the propagation of the undifferentiated cells, is an important threat that prevents any clinical use of such genetically altered cells. Also, all these four transcription factors are highly expressed in cancer tissues [17-20]. Reactivation

*Corresponding author: Alireza Shoae-Hassani, Applied Cell Sciencs department (Cell therapy Department), School of Advanced Technologies in Medicine, Tehran University of Medical Sciences, Tehran, Iran, Tel: 989121454878; E-mail: Cell.therapy@yahoo.com

Received Frbruary 22, 2014; Accepted June 05, 2014; Published June 07, 2014

Citation: Mohseni R, Hamidieh AA, Verdi J, Hassani AS (2014) Safe Transplantation of Pluripotent Stem Cell by Preventing Teratoma Formation. J Stem Cell Res Ther 4: 212. doi:10.4172/2157-7633.1000212

Copyright: (c) 2014 Mohseni R, et al. This is an open-access article distributed under the terms of the Creative Commons Attribution License, which permits unrestricted use, distribution, and reproduction in any medium, provided the original author and source are credited. 


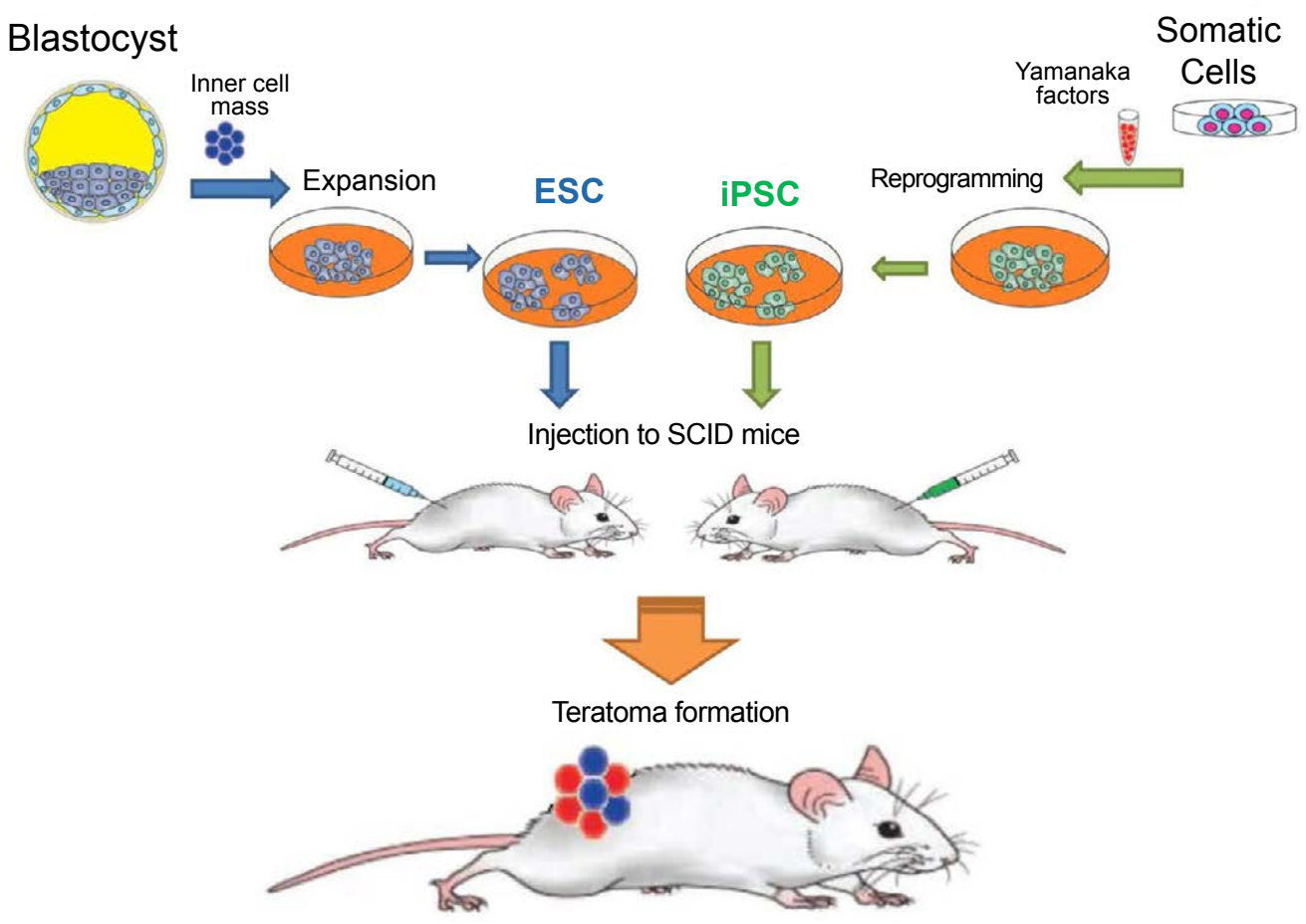

Figure 1: Schematic of teratoma formation. An overview of teratoma formation: culture of PSCs until the desired amount is achieved. The cells are harvested and with equal volume of liquid Matrigel injected to the SCID mice models for teratoma formation.

of the reprogramming transcripts can dispose iPSCs to genomic instability [21]. In 2011, Gore et al. have been shown that the mutations occur in the somatic codons during reprogramming [22] and a study by Hussein et al demonstrated the copy number variation of iPSCs during the reprogramming process [23]. The comparison of teratoma formation between ESCs and iPSCs is indicated by some details in the Table 1.

In most reports, teratoma formation was not reported after transplantation of differentiated grafts derived from ESCs [24,25]. These studies, however, were xenograft transplantations (i.e., human cells into a rat host), suggesting that the lack of tumor formation might be caused by severe immune-rejection due to transplantation from different species. Indeed, allograft experiments resulted in tumor formation even though the cells had been differentiated for more than 14 days in vitro, possibly due to a small number of undifferentiated pluripotent cells in the graft [26]. Some observations have been shown that not only undifferentiated human ESCs but also ESCs proliferating neural progenitors can produce tumors $[27,28]$. The study by Lee and colleagues shows that a critical threshold of undifferentiated human ESCs is required for teratoma formation to occur. Theoretically, a single undifferentiated ESC should be sufficient to populate a tumor; however, various factors may prevent teratoma formation [29]. Depends on the delivery site of pluripotent stem cell and also method of administration, it is possible that even fewer numbers of pluripotent cells lead to tumor formation. Several studies on allogeneic models of ESC transplantation was revealed that as few as 500 ESCs can lead to teratoma formation in immunodeficient state and between 50,000 and 100,000 cells are required for tumor formation in immunocompetency [30]. However there are differences between mouse and human pluripotent stem cells also this phenomenon could be related to the heterogeneity of phenotypically defined ESC population. For instance the E-Ras gene promotes the formation of teratomas by mouse ESCs but its human orthologue is not expressed in human ESCs [31]. So the behavior of transplanted mouse ESCs would not accurately reflect the behavior of transplanted human ESCs. Therefore the benefit of nonhuman primate models is more appropriate to demonstrate the safety of human pluripotent stem cell-based therapies. Interestingly, it has been reported that the teratoma growth is accelerated in male immunocompetent mice and xenogeneic rats. It means the teratoma growth might be supported by male hormones. The risk of teratoma formation appears to be influenced by a complex interaction between sex and immune status that needs further exploration [32].

Inflammation is the main driving force for the commencement of tumor development. Macrophage migration inhibitory factor (MIF) is an important regulator of host immune responses and also is recognized as a pro-tumorigenic factor [33] and is over-expressed in many tumors. Monocyte chemo-attractant protein 1 (MCP-1) is an essential chemokine, which acts through its receptor CCR2 to induce the migration and activation of macrophages and thus tumor progression [34]. In 2012, Wang et al demonstrated that PSCs transplantation stimulates an inflammatory response that involves the rapid recruitment and activation of macrophages, which may be a very important driving force in the formation of teratomas [35].

\section{Antibody-based Strategy for Preventing Teratoma}

The removal of rogue un-differentiated PSCs could be achieved by 1) destroying the remained undifferentiated PSCs in the differentiated tissue with specific antibodies, 2) removing the undifferentiated PSCs from the differentiated cell population, 3) removing pluripotent cells during the differentiation procedure, 4) inducing complete differentiation of leftover undifferentiated PSCs and 5) Inhibition from the dedifferentiating process for committed cells. To overcome the problem of teratoma formation, antibody based strategies has 


\begin{tabular}{|c|l|l|}
\hline Factors influencing tumorigenicity & HESCs & HiPSCs \\
\hline Origin & $\begin{array}{l}\text { Inner Cell M ass cells that have undergone very few } \\
\text { divisions }\end{array}$ & Mature somatic cells that have undergone many cell divisions \\
\hline Derivation & A relatively minor selection pressure* & $\begin{array}{l}\text { A major selection pressure owing to forced drastic change of epigenetic } \\
\text { landscape } \\
\text { May result in mutations and/or aberrations owing to reprogramming stress }\end{array}$ \\
\hline Viral integration & Not applicable & Most of the methods use viral vectors for reprogramming \\
\hline Oncogenes activation & Not applicable & $\begin{array}{l}\text { Current methods induce and up-regulate oncogenes in the reprogramming } \\
\text { process }\end{array}$ \\
\hline Cellular adaptation & $\begin{array}{l}\text { Prolonged growth in culture often results in gains of } \\
\text { chromosomes } 12,17,20 \text { and } \mathrm{X}\end{array}$ & Prolonged growth in culture often results in gains of chromosome 12 \\
\hline
\end{tabular}

Table 1: Comparison of the tumorigenicity between ESCs and iPSCs.

been used to remove the undifferentiated ESCs before transplantation. Among these a cytotoxic antibody against podocalyxin-like protein1(PODXL) can induce death to ESCs [36] but PODXL is expressed in many of human tissues and making it improper for elimination of the ESCs within the differentiating culture [37]. The immune-depletion of ESCs with the antibody mixture against multiple specific surface markers such as stage specific embryonic antigen 5 (SSEA5), CD9, CD30, CD50 and CD200 that referred to as the pluripotency surface markers could remove ESCs from differentiating cultures and reduce the teratoma risk [38]. The expression of SSEA5 is relatively specific for human ESC but the other surface marker is expressed in differentiated tissues [39], so the antibody-selection of ESCs could be limited by the specificity of the expression of their specific surface markers.

There is another limitation for the antibody based strategies and the problem is that some progenitor cells could dedifferentiate into pluripotent cells after transplantation and leading to teratoma formation [40]. It has been reported that natural killer cells are not important for the rejection of human PSCs in vivo [41]; however, in addition to antibody based strategies there are reports on the complement dependent control of teratoma formation that involves the innate immunity. In 2006 Koch et al. demonstrated that the complement system contributes to the control of teratoma growth after transplantation of ESCs [42]. In 2011, Kim et al presented a protocol that could inhibit teratoma formation near $99 \%$. They claimed that two consecutive MACS (magnetic activated cell sorter) separations upon simultaneous staining of two different ESC markers, SSEA-3 and TRA-1-60, completely depleted undifferentiated ESCs [43]. Recently it was demonstrated that an antibody against Claudin-6 (a cytotoxinconjugated antibody that targets undifferentiated cells; and Clostridium perfringens enterotoxin, a toxin that binds several Claudins) efficiently kills undifferentiated cells, thus eliminating the tumorigenic potential and teratoma formation of human pluripotent stem cell-containing cultures [44].

\section{Small molecules for Preventing Teratoma}

Small molecule targeting of pluripotent stem cell specific antiapoptotic factors is an effective strategy to eliminate the risk of teratomas occurrence in pluripotent stem cell-based therapy. In 2004, Bieberich and colleagues reported the selective apoptosis of pluripotent stem cells by novel ceramide analogue that prevents teratoma formation. They were reported that undifferentiated ESCs could be eliminated from cultures of ESC-derived neuronal cells by treatment with ceramide analogue N-oleoyl serinol [45]. Increased level of ceramide is a part of a mechanism that promotes programmed cell death during the development of the mouse brain. The addition of ceramide analogues to mouse ESCs eliminates the undifferentiated cells, but leaves those that have differentiated without any cytotoxic effect [46]. In a study concerning teratoma formation, the levels of a growth factor from the
EGF-CFC family (Cripto) were down regulated by generating a Cripto knock-out mouse. Cripto is over-expressed in a wide range of epithelial cancers [47] and its repression enhances neuronal differentiation. When Cripto knock-out ESCs were grown in the presence of FGF-8, and after grafting to immunosuppressed hemiparkinsonian rats, the Cripto negative ESC-derived grafts contained large numbers of dopaminergicpositive neurons without any teratomas [48]. In 2013, researchers in Korea found that quercetin and YM155-induced selective cell death is enough to inhibit teratoma formation after transplantation of human pluripotent stem cell-derived cells [49]. YM155 is an antagonist for surviving effect in pluripotent cells and quercetin (QC), a dietary flavonoid, is widely found in fruits (like apple), vegetables and green tea. QC has the ability to suppress various types of cancer cells and tumor growth, which are related, to expression of surviving [50]. PSCs are likely critically dependent, for their survival and self-renewal, on relatively few anti-apoptotic genes like $B c l 10$ and survivin that are highly expressed in ESCs. ABT737 and QC, inhibiting Bcl-2 family proteins and survivin, respectively, triggered apoptosis of ESCs and iPSCs but not that of their differentiated derivatives. QC treatment does not seem to influence the differentiation of PSCs into three germ layer lineages [49]. FTY720 (the pro-drug analogue for sphingosine-1-phosphate) is already used in clinical trials to treat multiple sclerosis, mainly because of its immunosuppressing activity (Davis et al., 2005). The experiments showed that FTY720 eliminates teratoma-forming cells and protects neural progenitor cells from $\mathrm{N}$-oleoyl serinol-inducible apoptosis [51]

It has been shown that encapsulation of ESC with membranes ( $2.2 \%$ barium alginate) prevented the teratomas formation up to three months. Also it has been reported the mouse ESCs but not the human ESCs formed aggregates within the alginate capsules, which remained free of fibrosis [52].

\section{Using suicide Gene into the Pluripotency Locus}

The marker genes for ESCs and those required for iPSCs production including Oct4, Sox2, Klf4, cMyc, Lin28, and Nanog. These genes that related to the pluripotency are linked to stem cell tumorigenesis [6]. It was reported that gancyclovir treatment could prevent the teratoma formation of ESCs with a transgenic thymidine kinase gene driven by a mouse Nanog promoter [53], however the random integration of the transgene in the genome could change the promoter activity and increase the risk of cancer. In 2012, Rong et al., have been designed a strategy to introduce a suicide gene into a genetic locus that is specifically expressed in pluripotent cells but not in their differentiated derivatives [54]. They chose the pluripotency gene Nanog locus that is specifically expressed in pluripotent cells. The Nanog is rapidly down-regulated post-epiblast stage during embryonic development [55]. Nanog, is phosphorylated at multiple Ser/Thr-Pro motifs and the phosphorylation stimulates the interaction between Nanog and the prolyl isomerase Pin1, that cause Nanog stabilization by suppressing 
its ubiquitination. Inhibition of Pin1 activity and destroying the Pin1Nanog interaction in ESCs suppresses their capability to self-renew and to form teratomas [56].

\section{Cell Signaling and Teratoma}

Previously it was thought that the pluripotent marker Oct-4 is enough to predict the formation of teratomas and the removal of Oct-4-positive cells could prevent teratomas from developing after transplantation [57]. But we know that the Oct-4 negative stem cells could contribute to the teratoma formation. Various signaling pathways and cytokines, including fibroblast growth factor (FGF), bone morphogenic protein (BMP4) [58,59], transforming growth factor beta (TGF $\beta$ ), p38 MAPK [60], Janus kinase (JNK) pathway and ERK pathway [61] regulates ESC self-renewal and survival. Some growth factors also influence apoptosis via PKC, PI3K (PhosphatidylInositol kinase), and Akt pathways [62] and the decrease in the levels of these factors could initiate teratoma formation and enhance its size and incidence.

The cyclin dependent kinase (CDK) inhibitor, p18INK4c, is a known tumor suppressor that can inhibit self-renewal of tumor cells or adult stem cells [63]. Also experiments have been shown that the teratoma volume from p18-overexpressing ESCs was found to be significantly reduced compared to the control group [64]. So, p18 inhibits teratoma growth, which is consistent with a role for p18 as a tumor suppressor in somatic tissues [65].

The B-cell lymphoma 2 (Bcl-2) families, consisting more than 25 pro- and anti-apoptotic members, regulates the caspase cascade and apoptosis [66]. These proteins maintain a balance between new cells and old one. ESCs over-expressing $\mathrm{Bcl}-2$ proliferate in feeder-free cultures when supplemented with leukemia inhibitory factor (LIF) [67], indicating that attenuation of apoptosis is critical for ESCs survival and self-renewal. The teratomas generated from $\mathrm{Bcl}-2$ over-expressing cells are significantly larger than control cells, suggesting that $B c l$ enhances ESCs survival and teratoma formation in vivo [68]. Some studies demonstrated that a distinct mitochondrial p53 function regulates apoptotic signals in ESCs $[69,70]$. The mitochondrial localization of p53 was suggested to be the result of a post-translational modification of undifferentiated ESCs [69]. The p53 dependent transcription under certain stress condition could induce differentiation by blocking Nanog expression. Interestingly, down-regulation of tumor suppressors in the p53 pathway increases the efficiency of the reprogramming and enables it with only two factors including OCT4 and SOX2 [71,72]. Also in 2008, Schieke et al. have been demonstrated that the degree of overall mammalian target of rapamycin (mTOR) activation and the mTOR inhibitor rapamycin reduces metabolic rate, augments differentiation, and inhibits teratoma formation of the embryonic stem cells with a high metabolic rate. They concluded that mitochondrial metabolism modulates differentiation and teratoma formation capacity in mouse embryonic stem cells [73]. In 2012, Hannesdottir et al. have been found a role for signal transducer and activator of transcription 1 (STAT1) in protecting from teratoma formation by inducing apoptosis and eliminating premature or aberrantly formed follicles which have the potential to transform into teratomas [74]. STAT1 encodes an inducible transcription factor and mediates the intracellular response to type I/II interferons [75], and serves as an important effector in the innate immune response [76] and a regulator of cell death [77].

\section{Teratoma Restriction by preventing Angiogenesis}

Angiogenesis is the proliferation of a network of blood vessels that penetrates into tumors, supplying nutrients and oxygen and removing leftover products. We now show that $\beta 1$ integrin plays an essential role during angiogenesis. In 1997, researchers have been shown that $\beta 1$ integrin is essential for teratoma growth and angiogenesis [78]. Anti-angiogenic therapies to limit the growth of tumors are under investigation [79]. Usually the host vasculatures expanded into teratoma and support the nutriention supply of teratoma [80]. The discovery and characterization of teratoma-derived angiogenesis processes will contribute to our understanding of how teratoma regulates angiogenesis and provide a therapeutic strategy for teratoma formation after ESCs therapy. Based upon the investigations, the agents targeting endothelial cells differentiated from ESCs or preventing host vasculatures from expanding into teratomas may be a choice to prevent and treat teratomas formed by undifferentiated ES cells.

The ESCs that passaged by collagenase could not to generate teratoma when single cell suspension is prepared using trypsin digestion, dissimilar to efficient teratoma formation by trypsin adapted ESCs [81]. Given that teratoma formation must be prevented in clinical cases, this result in the single cell suspension containing ESCs provides promise for a cell therapy strategy.

\section{Diagnosis of Teratoma Formation}

As clinical translation of pluripotent stem cells progresses, the use of "gold standard" teratoma formation for examination of pluripotency and/or other PSCs manners in acting in vivo will continue to be essential for researchers (Figure 2). In all the conventional teratoma assays using severe combined immunodeficient (SCID) mice and teratomas are formed after injection of clusters of PSCs. The teratoma usually expanded and shows cystic elements that are histologically characterized as nervous tissue, keratinizing stratified squamous epithelium (ectoderm), smooth muscle, striated muscle, cartilage, bone (mesoderm), and glandular tissue in the form of gut- and respiratorylike epithelia (endoderm) (Figure 2).

Teratoma tissues are composed of undifferentiated cells, which expressing SSEA-3, SSEA-4, Tra-1-60 and Tra-1-81. These cells are more differentiated but have less proliferation capacity in compare to ESCs and they would be difficult to form teratoma like masses in vivo. Also fluorescence activated cell sorter (FACS analysis) revealed that ESCs derived teratomas express a high level of CD56, and CD56 would be a good indicator for teratoma formation of ESCs in vivo. CD56 is a surface glycoprotein that frequently expressed on the surface of neurons, glia, skeletal muscle and natural killer cells [82]. It is intensely expressed in the mesenchyme and is a marker of early neuroectodermal differentiation [83], which has been used to identify neural differentiation of human ESCs [84].

Flow-cytometry assay is limited by the sensitivity and its reliable limit is at $10^{4}$ in the background of $10^{6}$ cells with two color assay. Also it requires large sample sizes for testing. Polymerase chain reaction (PCR) similarly needs large sample sizes for statistically reliable testing and is not truly quantitative.

As we know the reporter gene imaging is an ideal technology for monitoring long-term stem cell viability, death, and proliferation. In 2011, Su et al. were developed a bioluminescence assay for detection of teratoma formation. They transduced ESCs with a double fusion reporter gene that consists of firefly luciferase and enhanced green fluorescent protein (Fluc-eGFP) [80]. There were no apparent side effects of the reporter gene on maintaining stem cell state, cell viability and cell proliferation. Therefore this technique enables us to track cells by noninvasive imaging. 
Citation: Mohseni R, Hamidieh AA, Verdi J, Hassani AS (2014) Safe Transplantation of Pluripotent Stem Cell by Preventing Teratoma Formation. J Stem Cell Res Ther 4: 212. doi:10.4172/2157-7633.1000212

Page 5 of 7
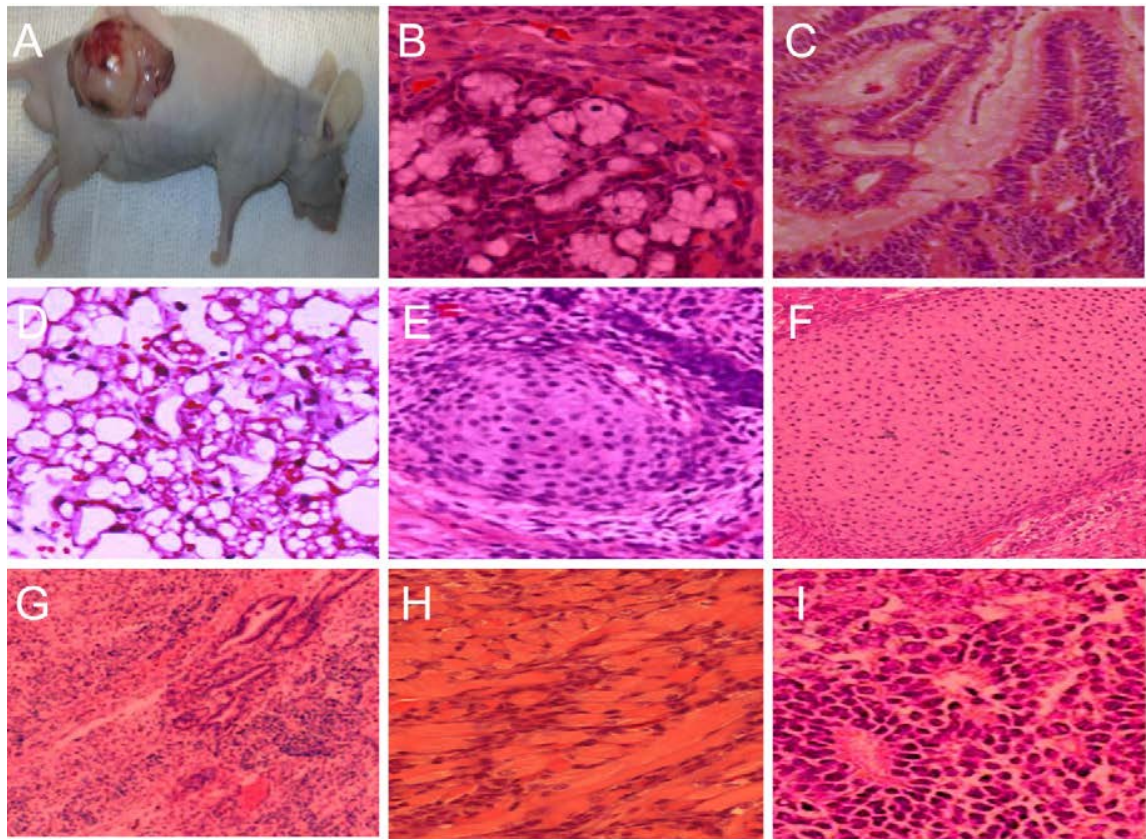

Figure 2: Teratoma growth in subcutaneous tissue of nude mice and histological characterization of a teratoma formed from undifferentiated mouse ESCs. (A) The teratoma mass formed in the subcutaneous region of a nude mouse, (B) Glandular epithelium (endoderm), (C) guts epithelium (endoderm), (D) adipocyte (mesoderm) tissue, (E) Cartilage (mesoderm) tissue, (F) an osteoid like (mesoderm) tissue, (G) smooth muscle cell (mesoderm), (H) striated muscle tissue (mesoderm) and (I) neural epithelium (ectoderm).

Another method to survey the teratoma production could be the transplantation of PSCs onto the chorio-allantoic membrane (CAM) of chicken embryos. This method possess the advantages of the in vivo experiment with the simplicity of an in vitro conditions such as quick and cheap without ethical concerns. The CAM is located at the periphery of the embryo as a vascularized extraembryonic natural immunodeficient tissue. Tumor growth in CAM could be observed within days $(\sim 5-10 \mathrm{~mm}$ in Size $)$ and much similarity to teratomas [85].

\section{Conclusion}

Now there are some methods available to eliminate undifferentiated cells remained from pluripotent stem cells. Some of these methods are efficient in some extent but we still need an efficient and cost effective method for this purpose. The kinetics of the teratoma formation is depend on the number of remaining PSCs and it could take a long time for a small number of PSCs to form teratomas. Therefore, the batchto-batch deviation in the lineage specific differentiation will make it a tediously long and not decisive attempt to evaluate the teratoma risk of the PSC-derived cells prepared for therapeutic approaches. Therefore, an efficient approach beyond the mentioned points in this article to eliminate the teratoma risk associated with PSCs would greatly facilitate the development of the ESC/iPSC-based cell therapy.

\section{References}

1. Noureddini M, Verdi J, Mortazavi-Tabatabaei SA, Sharif S, Azimi A, et al (2012) Human endometrial stem cell neurogenesis in response to NGF and bFGF. Cell Biol Int 36: 961-966. [PubMed]

2. Shoae-Hassani A, Mortazavi-Tabatabaei SA, Sharif S, Seifalian AM, Azimi A et al. (2013a) Differentiation of human endometrial stem cells into urothelial cells on a three-dimensional nanofibrous silk-collagen scaffold: an autologous cell resource for reconstruction of the urinary bladder wall. J Tissue Eng Regen Med. [PubMed]

3. Shoae-Hassani A, Sharif S, Seifalian AM, Mortazavi-Tabatabaei SA, Rezaie $S$, et al. (2013b) Endometrial stem cell differentiation into smooth muscle cell: a novel approach for bladder tissue engineering in women. BJU Int 112: 854 863. [PubMed]

4. Takahashi K, Tanabe K, Ohnuki M, Narita M, Ichisaka T, et al. (2007) Induction of pluripotent stem cells from adult human fibroblasts by defined factors. Cell 131: 861-872. [PubMed]

5. Shoae-Hassani A, Sharif S, Verdi J (2011) The neurosteroid dehydroepiandrosterone could improve somatic cell reprogramming. Cell Bio Int 35: 1037-1041. [PubMed]

6. Blum B, Benvenisty $N(2008)$ The tumorigenicity of human embryonic stem cells. Adv Cancer Res 100: 133-158. [PubMed]

7. Ben-David U, Benvenisty N (2011) The tumorigenicity of human embryonic and induced pluripotent stem cells. Nat Rev Cancer 11: 268-277. [PubMed]

8. Cooke MJ, Stojkovic M, Przyborski SA (2006) Growth of teratomas derived from human pluripotent stem cells is influenced by the graft site. Stem Cells Dev 15: 254-259. [PubMed]

9. Shih C, Forman SJ, Chu P, Forman SJ, Chu P et al. (2007) Human embryonic stem cells are prone to generate primitive, undifferentiated tumors in engrafted human fetal tissues in severe combined immunodeficient mice. Stem Cells Dev 16: 893-902. [PubMed]

10. Prokhorova TA, Harkness LM, Frandsen U, Ditzel N, Schroder HD, et al. (2008) Teratoma formation by human embryonic stem cells is site dependent and enhanced by the presence of Matrigel. Stem Cells Dev 18: 47-54. [PubMed]

11. Eilers M, Eisenman RN (2008) Myc's broad reach. Genes Dev 22: 2755-2766. [PubMed]

12. Lensch MW, Schlaeger TM, Zon LI, Daley GQ (2007) Teratoma Formation Assays with Human Embryonic Stem Cells: A Rationale for One Type of Human-Animal Chimera. Cell stem cell 1: 253-258. [PubMed]

13. Amariglio N, Hirshberg A, Scheithauer BW, Cohen $Y$, Loewenthal $R$, et al (2009) Donor-derived brain tumor following neural stem cell transplantation in an ataxia telangiectasia patient. PLoS Med 6: 1000029. [PubMed]

14. Fukuda $\mathrm{H}$, Takahashi J, Watanabe $\mathrm{K}$, Hayashi $\mathrm{H}$, Morizane A, et al. (2006) Fluorescence-activated cell sorting-based purification of embryonic stem cell derived neural precursors averts tumor formation after transplantation. Stem Cells 24: 763-771. [PubMed] 
Citation: Mohseni R, Hamidieh AA, Verdi J, Hassani AS (2014) Safe Transplantation of Pluripotent Stem Cell by Preventing Teratoma Formation. J Stem Cell Res Ther 4: 212. doi:10.4172/2157-7633.1000212

Page 6 of 7

15. Chung S, Shin BS, Hedlund E, Pruszak J, Ferree A, et al. (2006) Genetic selection of sox1GFP-expressing neural precursors removes residual tumorigenic pluripotent stem cells and attenuates tumor formation after transplantation. J Neurochem 97: 1467-1480. [PubMed]

16. Geron Corporation (2010) Geron's IND for Spinal Cord Injury Placed on Hold [Press release].

17. Albihn A, Johnsen Jl, Henriksson MA (2010) MYC in oncogenesis and as a target for cancer therapies. Adv Cancer Res 107: 163-224. [PubMed]

18. Asadi MH, Mowla SJ, Fathi F, Aleyasin A, Asadzadeh J, et al. (2010) OCT4B1, a novel spliced variant of OCT4, is highly expressed in gastric cancer and acts as an anti-apoptotic factor. Int J Cancer 128: 2645-2652. [PubMed]

19. 19. Sholl LM, Barletta JA, Yeap BY, Chirieac LR, Hornick JL (2010) Sox2 protein expression is an independent poor prognostic indicator in stage I lung adenocarcinoma. Am J Surg Pathol 34: 1193-1198. [ PubMed]

20. Tian Y, Luo A, Cai Y, Su Q, Ding F, et al. (2010) MicroRNA-10b promotes migration and invasion through KLF4 in human esophageal cancer cell lines. J Biol Chem 285: 7986-7994. [PubMed]

21. Ramos-Mejia V, Munoz-Lopez M, Garcia-Perez JL, Menendez P (2010) iPSC lines that do not silence the expression of the ectopic reprogramming factors may display enhanced propensity to genomic instability. Cell Res 20: 10921095. [PubMed]

22. Gore A, Li Z, Fung HL, Young JE, Agarwal S, et al. (2011) Somatic coding mutations in human induced pluripotent stem cells. Nature 471: 63-67. [PubMed]

23. Hussein SM, Batada NN, Vuoristo S, Ching RW, Autio R, et al. (2011) Copy number variation and selection during reprogramming to pluripotency. Nature 471: 58-62. [PubMed]

24. Kim JH, Auerbach JM, Rodriguez-Gomez JA, Velasco I, Gavin D, et al. (2002) Dopamine neurons derived from embryonic stem cells function in an animal model of Parkinson's disease. Nature 418: 50-56. [PubMed]

25. Zhang SC, Wernig M, Duncan ID, Brustle O, Thomson JA (2001) In vitro differentiation of transplantable neural precursors from human embryonic stem cells. Nat Biotechnol 19: 1129-1133. [PubMed]

26. Barberi T, Klivenyi P, Caligasan NY, Lee H, Kawamata H, et al. (2003) Neura subtype specification of fertilization and nuclear transfer embryonic stem cells and application in parkinsonian mice. Nat Biotechnol 10: 1200-1207. [PubMed]

27. Roy NS, Cleren C, Singh SK, Yang L, Beal MF, et al. (2006) Functional engraftment of human ES cell-derived dopaminergic neurons enriched by coculture with telomerase-immortalized midbrain astrocytes. Nat Med 12: 1259-1268. [PubMed]

28. Yang D, Zhang ZJ, Oldenburg M, Ayala M, Zhang SC (2008) Human embryonic stem cell-derived dopaminergic neurons reverse functional deficit in parkinsonian rats. Stem Cells 26: 55-63. [PubMed]

29. Lee AS, Tang C, Cao F, Xie X, van der Bogt K, et al. (2009) Effects of cell number on teratoma formation by human embryonic stem cells. Cell Cycle 8 : 2608-2612. [PubMed]

30. Harkany T, Andäng M, Kingma HJ, Görcs TJ, Holmgren CD, et al. (2004) Regionspecific generation of functional neurons from naive embryonic stem cells in adult brain. J Neurochem 88: 1229-1239. [PubMed]

31. Tanaka Y, Ikeda T, Kishi Y, Masuda S, Shibata $H$, et al. (2009) ERas Is expressed in primate embryonic stem cells but not related to tumorigenesis. Cell Transplant 18: 381-389. [PubMed]

32. Dressel R, Schindehutte J, Kuhlmann T, Elsner L, Novota P, et al. (2008) The Tumorigenicity of Mouse Embryonic Stem Cells and In Vitro Differentiated Neuronal Cells Is Controlled by the Recipients' Immune Response. PLoS One 3(7): e2622. [PubMed]

33. Bucala R, Donnelly SC (2007) Macrophage migration inhibitory factor: a probable link between inflammation and cancer. Immunity 26: 281-285. [PubMed]

34. Fujimoto $H$, Sangai T, Ishii G, Ikehara A, Nagashima T, et al. (2009) Stromal $\mathrm{MCP}-1$ in mammary tumors induces tumor-associated macrophage infiltration and contributes to tumor progression. Int J Cancer 125: 1276-1284. [PubMed]

35. Wang X, Chen T, Leng L, Fan J, Cao K, et al. (2012) MIF produced by Bone Marrow-Derived Macrophages contributes to teratoma progression after embryonic stem cell transplantation. Cancer Res 72: 2867-2878. [PubMed]
36. Choo AB, Tan HL, Ang SN, Fong WJ, Chin A, et al. (2008) Selection against undifferentiated human embryonic stem cells by a cytotoxic antibody recognizing podocalyxin-like protein-1. Stem Cells 26: 1454-1463. [PubMed]

37. Kershaw DB, Beck SG, Wharram BL, Wiggins JE, Goyal M, et al. (1997) Molecular cloning and characterization of human podocalyxin-like protein. Orthologous relationship to rabbit PCLP1 and rat podocalyxin. J Biol Chem 272: 15708-15714. [PubMed]

38. Tang C, Lee AS, Volkmer JP, Sahoo D, NagD, et al. (2011) An antibody against SSEA-5 glycan on human pluripotent stem cells enables removal of teratomaforming cells. Nat Biotechnol 29: 829-834. [PubMed]

39. Rubinstein E, Billard M, Plaisance S, Prenant M, Boucheix C (1993) Molecular cloning of the mouse equivalent of CD9 antigen. Thromb Res 71: 377-383. [PubMed]

40. Fujikawa T, Oh SH, Pi L, Hatch HM, Shupe T, et al. (2005) Teratoma formation leads to failure of treatment for type I diabetes using embryonic stem cellderived insulin-producing cells. Am J Pathol 166: 1781-1791. [PubMed]

41. Drukker M, Katchman H, Katz G, Even-Tov Friedman S, Shezen E, et al (2006) Human embryonic stem cells and their differentiated derivatives are less susceptible to immune rejection than adult cells. Stem Cells 24: 221-229. [PubMed]

42. Koch CA, Jordan CE, Platt JL (2006) Complement-dependent control of teratoma formation by embryonic stem cells. J Immunol 177: 4803-4809. [PubMed]

43. Kim HO, Huh YJ, Jang J, Choi Y, Kim DW, et al. (2011) Selective depletion of SSEA-3- and TRA-1-60-positive undifferentiated human embryonic stem cells by magnetic activated cell sorter (MACS). Tissue Eng Regen Med 8: 253-261.

44. Ben-David U, Nudel N, Benvenisty N (2013) Immunologic and chemical targeting of the tight-junction protein Claudin- 6 eliminates tumorigenic human pluripotent stem cells. Nat Commun 4: 1992. [PubMed]

45. Bieberich E, Silva J, Wang G, Krishnamurthy K, Condie BG (2004) Selective apoptosis of pluripotent mouse and human stem cell by novel ceramide analogues prevents teratoma formation and enriches for neural precursors in ES cell-derived neural transplants. J Cell Biol 167: 723-734. [PubMed]

46. Bieberich E, MacKinnon S, Silva J, Noggle S, Condie BG (2003) Regulation of cell death in mitotic neural progenitor cells by asymmetric distribution of prostate apoptosis response 4 (PAR-4) and simultaneous elevation of endogenous ceramide. J Cell Biol 162: 469-479. [PubMed]

47. Anisimov SV, Tarasov KV, Riordon D, Wobus AM, Boheler KR (2002) SAGE identification of differentiation responsive genes in P19 embryonic cells induced to form cardiomyocytes in vitro. Mech Dev 117: 25-74. [PubMed]

48. Parish CL, Parisi S, Persico MG, Arenas E, Minchiotti G (2005) Cripto as a target for improving embryonic stem cell-based therapy in Parkinson's disease. Stem Cells 23: 471-476. [PubMed]

49. Lee MO, Moon SH, Jeong HC, Yi JY, Lee TH, et al. (2013) Inhibition of pluripotent stem cell-derived teratoma formation by small molecules. Proc Natl Acad Sci USA 110: E3281-E3290. [PubMed]

50. Altieri DC (2008) Survivin, cancer networks and pathway-directed drug discovery. Nat Rev Cancer 8: 61-70. [PubMed]

51. Bieberich E (2008) Smart drugs for smarter stem cells: making SENSe (Sphingolipid-enhanced neural stem cells) of ceramide. Neurosignals 16: 124139. [PubMed]

52. Dean SK, Yulyana Y, Williams G, Sidhu KS, Tuch B (2006) Differentiation of encapsulated embryonic stem cells after transplantation. Transplantation 82: 1175-1184. [PubMed]

53. Cheng F, Ke Q, Chen F, Cai B, Gao Y, et al. (2012) Protecting against wayward human induced pluripotent stem cells with a suicide gene. Biomaterials 33 3195-3204. [PubMed]

54. Rong Z, Fu X, Wang M, Xu Y (2012) A scalable approach to prevent teratoma formation of human embryonic stem cells. J Biol Chem 287: 32338-32345. [PubMed]

55. Chambers I, Colby D, Robertson M, Nichols J, Lee S, et al. (2003) Functiona expression cloning of Nanog, a pluripotency sustaining factor in embryonic stem cells. Cell 113: 643-655. [PubMed]

56. Moretto-Zita M, Jin H, Shen Z, Zhao T, Briggs SP, et al. (2010) Phosphorylation 
Citation: Mohseni R, Hamidieh AA, Verdi J, Hassani AS (2014) Safe Transplantation of Pluripotent Stem Cell by Preventing Teratoma Formation. J Stem Cell Res Ther 4: 212. doi:10.4172/2157-7633.1000212

stabilizes Nanog by promoting its interaction with Pin1. Proc Natl Acad Sci USA 107: 13312-13317. [PubMed]

57. Campbell PA, Perez-Iratxeta C, Andrade-Navarro MA, Rudnicki MA (2007) Oct4 targets regulatory nodes to modulate stem cell function. PLoS ONE 2: e553. [PubMed]

58. Qi X, Li TG, Hao J, Hu J, Wang J, et al. (2004) BMP4 supports self-renewal of embryonic stem cells by inhibiting mitogen-activated protein kinase pathways. Proc Natl Acad Sci USA 101: 6027-6032. [PubMed]

59. Xu RH, Peck RM, Li DS, Feng X, Ludwig T, et al. (2005) Basic FGF and suppression of BMP signaling sustain undifferentiated proliferation of human ES cells. Nat Methods 2: 185-190. [PubMed]

60. Watabe T, Miyazono K (2009) Roles of TGF-beta family signaling in stem cell renewal and differentiation. Cell Res 19: 103-115. [PubMed]

61. Brill LM, Xiong W, Lee KB, Ficarro SB, Crain A, et al. (2009) Phosphoproteomic analysis of human embryonic stem cells. Cell Stem Cell 5: 204-213. [PubMed]

62. Thompson JE, Thompson CB (2004) Putting the rap on Akt. J Clin Oncol 22: 4217-4226. [PubMed]

63. Franklin DS, Godfrey VL, O'Brien DA, Deng C, Xiong Y (2000) Functional collaboration between different cyclin-dependent kinase inhibitors suppresses tumor growth with distinct tissue specificity. Mol Cell Biol 20: 6147-6158. [PubMed]

64. Li Y, Pal R, Sung LY, Feng H, Miao W, et al. (2012) An opposite effect of the CDK inhibitor, p18INK4c on embryonic stem cells compared with tumor and adult stem cells. PLoS ONE 7: e45212. [PubMed]

65. Franklin DS, Godfrey VL, Lee H, Kovalev GI, Schoonhoven R, et al. (1998) CDK inhibitors p18(INK4c) and p27(Kip1) mediate two separate pathways to collaboratively suppress pituitary tumorigenesis. Genes Dev 12: 2899-2911. [PubMed]

66. Reed JC, Pellecchia M (2005) Apoptosis-based therapies for hematologic malignancies. Blood 106: 408-418. [PubMed]

67. Yamane T, Dylla SJ, Muijtjens M, Weissman IL (2005) Enforced Bcl-2 expression overrides serum and feeder cell requirements for mouse embryonic stem cell self-renewal. Proc Natl Acad Sci USA 102: 3312-3317. [PubMed]

68. Bai H, Chen K, Gao YX, Arzigian M, Xie YL, et al. (2012) Bcl-xL enhances single-cell survival and expansion of human embryonic stem cells without affecting self-renewal. Stem Cell Res 8: 26-37. [PubMed]

69. Qin H, Yu T, Qing T, Liu Y, Zhao Y, et al. (2007) Regulation of apoptosis and differentiation by p53 in human embryonic stem cells. J Biol Chem 282: 5842 5852. [PubMed]

70. Han MK, Song EK, Guo Y, Ou X, Mantel C, et al. (2008) SIRT1 regulates apoptosis and Nanog expression in mouse embryonic stem cells by controlling p53 subcellular localization. Cell Stem Cell 2: 241-251. [PubMed]

71. Hong H, Takahashi K, Ichisaka T, Aoi T, Kanagawa O, et al. (2009) Suppression of induced pluripotent stem cell generation by the p53-p21 pathway. Nature 460: 1132-1135. [PubMed]

72. Marion RM, Strati K, Li H, Murga M, Blanco R, et al. (2009) A p53-mediated DNA damage response limits reprogramming to ensure iPS cell genomic integrity. Nature 460: 1149-1153. [PubMed]

73. Schieke SM, Ma M, Cao L, McCoy JP, Liu C, et al. (2008) Mitochondria metabolism modulates differentiation and teratoma formation capacity in mouse embryonic stem cells. J Biol Chem 283: 28506-28512. [PubMed]

74. Hannesdottir L, Daschil N, Philipp S, Tymoszuk P, Muller-Holzner E, et al. (2012) MMTV-neu mice deficient in STAT1 are susceptible to develop ovarian teratomas. Int J Dev Biol 56: 279-283. [PubMed]

75. Schindler C, Plumlee C (2008) Inteferons pen the JAK-STAT pathway. Semin Cell Dev Biol 19: 311-318. [PubMed]

76. Durbin JE, Hackenmiller R, Simon MC, Levy DE (1996) Targeted disruption of the mouse Stat 1 gene results in compromised innate immunity to viral disease. Cell 84: 443-450. [PubMed]

77. Kim HS, Lee MS (2007) STAT1 as a key modulator of cell death. Cell Signal 19: 454-465. [PubMed]

78. Bloch W, Forsberg E, Lentini S, Brakebusch C, Martin K, et al. (1997) $\beta 1$ Integrin is essential for teratoma growth and angiogenesis. J Cell Biol 139 265-270. [PubMed]

79. Kerbel RS (2008) Tumor angiogenesis. N Engl J Med 358: 2039-2049. [PubMed]

80. Su W, Zhou M, Zheng Y, Fan Y, Han Z, et al. (2011) Bioluminescence Reporter Gene Imaging Characterize Human Embryonic Stem Cell-Derived Teratoma Formation. J Cell Biochem 112: 840-848. [PubMed]

81. Ellerström C, Strehl R, Noaksson K, Hyllner J, Semb H (2007) Facilitated expansion of human embryonic stem cells by single-cell enzymatic dissociation. Stem Cells 25: 1590. [PubMed]

82. Pruszak J, Sonntag KC, Aung MH, Sanchez-Pernaute R, Isacson O (2007) Markers and methods for cell sorting of human embryonic stem cell-derived neural cell populations. Stem cells 25: 2257-2268. [PubMed]

83. Reubinoff BE, Itsykson P, Turetsky T, Pera MF, Reinhartz E, et al. (2001) Neural progenitors from human embryonic stem cells. Nat Biotechnol 19: 11341140. [PubMed]

84. Sundberg $M$, Jansson $L$, Ketolainen J, Pihlajamaki $H$, Suuronen $R$, et al. (2009) CD marker expression profiles of human embryonic stem cells and their neural derivatives, determined using flow-cytometric analysis, reveal a nove CD marker for exclusion of pluripotent stem cells. Stem Cell Res 2: 113-124. [PubMed]

85. Hagedorn M, Javerzat S, Gilges D, Meyre A, de Lafarge B, et al. (2005) Accessing key steps of human tumor progression in vivo by using an avian embryo model. Proc Natl Acad Sci USA 102: 1643-1648. [PubMed] 